\title{
A simple equation to estimate body fat percentage in children with overweight or obesity: a retrospective study.
}

\author{
Ernesto Cortés-Castell ${ }^{1}$ ， Mercedes Juste ${ }^{1}$ ， Antonio Palazón-Bru ${ }^{\text {corresp., }}{ }^{2}$, Laura Monge ${ }^{1}$, Francisco Sánchez- \\ Ferrer $^{1}$, María M Rizo-Baeza ${ }^{3}$ \\ 1 Pharmacology, Pediatrics and Organic Chemistry Department, Miguel Hernández University, San Juan de Alicante, Alicante, Spain \\ 2 Clinical Medicine Department, Miguel Hernández University, San Juan de Alicante, Alicante, Spain \\ 3 Nursing Department, University of Alicante, San Vicente del Raspeig, Alicate, Spain \\ Corresponding Author: Antonio Palazón-Bru \\ Email address: antonio.pb23@gmail.com
}

Background. Dual-energy X-ray absorptiometry (DXA) provides separate measurements of fat mass, fat-free mass and bone mass, and is a quick, accurate, and safe technique, yet one that is not readily available in routine clinical practice. Consequently, we aimed to develop statistical formulas to predict fat mass (\%) and fat mass index (FMI) with simple parameters (age, sex, weight and height). Methods. We conducted a retrospective observational cross-sectional study in 416 overweight or obese patients aged 4 to 18 years that involved assessing adiposity by DXA (fat mass percentage and FMI), body mass index (BMI), sex and age. We randomly divided the sample into two parts (construction and validation). In the construction sample, we developed formulas to predict fat mass and FMI using linear multiple regression models. The formulas were validated in the other sample, calculating the intraclass correlation coefficient via bootstrapping. Results. The fat mass percentage formula had a coefficient of determination of 0.65 . This value was 0.86 for FMI. In the validation, the constructed formulas had an intraclass correlation coefficient of 0.77 for fat mass percentage and 0.92 for FMI. Conclusions. Our predictive formulas accurately predicted fat mass and FMI with simple parameters (BMI, sex and age) in children with overweight and obesity. The proposed methodology could be applied in other fields. Further studies are needed to externally validate these formulas. 
1 COVER PAGE:

2 Title: A simple equation to estimate body fat percentage in children with overweight or obesity:

3 a retrospective study.

4 Authors: Ernesto Cortés-Castell ${ }^{1}$, Mercedes Juste ${ }^{1}$, Antonio Palazón-Bru², Laura Monge ${ }^{1}$,

5 Francisco Sánchez-Ferrer ${ }^{1}$, María Mercedes Rizo-Baeza ${ }^{3}$.

6 Institutions:

7 1: Pharmacology, Pediatrics and Organic Chemistry Department, Miguel Hernández University,

8 San Juan de Alicante, Alicante, Spain.

9 2: Clinical Medicine Department, Miguel Hernández University, San Juan de Alicante, Alicante, 10 Spain.

11 3: Nursing Department, University of Alicante, San Vicente del Raspeig, Alicante, Spain.

13 Corresponding author: Prof. Antonio Palazón-Bru, PhD. Clinical Medicine Department, Miguel

14 Hernández University, Carretera de Valencia - Alicante S/N, 03550 San Juan de Alicante.

15 Telephone: +34 965919449. Fax: +34 965919450. E-mail: antonio.pb23@gmail.com 
Background. Dual-energy X-ray absorptiometry (DXA) provides separate measurements of fat mass, fat-free mass and bone mass, and is a quick, accurate, and safe technique, yet one that is not readily available in routine clinical practice. Consequently, we aimed to develop statistical formulas to predict fat mass (\%) and fat mass index (FMI) with simple parameters (age, sex, weight and height).

Methods. We conducted a retrospective observational cross-sectional study in 416 overweight or obese patients aged 4 to 18 years that involved assessing adiposity by DXA (fat mass percentage and FMI), body mass index (BMI), sex and age. We randomly divided the sample into two parts (construction and validation). In the construction sample, we developed formulas to predict fat mass and FMI using linear multiple regression models. The formulas were validated in the other sample, calculating the intraclass correlation coefficient via bootstrapping.

Results. The fat mass percentage formula had a coefficient of determination of 0.65 . This value was 0.86 for FMI. In the validation, the constructed formulas had an intraclass correlation coefficient of 0.77 for fat mass percentage and 0.92 for FMI.

Conclusions. Our predictive formulas accurately predicted fat mass and FMI with simple parameters (BMI, sex and age) in children with overweight and obesity. The proposed methodology could be applied in other fields. Further studies are needed to externally validate these formulas. 


\section{INTRODUCTION}

During childhood and adolescence, there is a balanced growth of the different body components: skeletal muscle, fat, bone and viscera. Obesity involves an increase in body weight combined with an imbalance between these components, with a higher proportion of body fat (Ballabriga \& Carrascosa, 2006), and is defined as an excess of body fat relative to total body mass (Himes \& Dietz, 1994). There is nearly universal consensus in defining overweight as a body mass index (BMI $\left[\mathrm{kg} / \mathrm{m}^{2}\right]$ ) between the $85^{\text {th }}$ and $95^{\text {th }}$ percentiles and obesity as a BMI at the $95^{\text {th }}$ percentile or greater (Power, Lake \& Cole, 1997; Prentice, 1998; Serra Majem et al., 2002; Cole \& Lobstein, 2012). Determinants of body fat in children and adolescents include socioeconomic factors, education of the mother, physical activity and physical fitness (Moliner-Urdiales et al., 2009; van Sluijs et al., 2010; Gómez-Martínez et al., 2012).

Age- and sex-specific BMI percentile values are easy to calculate and is strongly correlated with the body fat percentage, especially for high BMI values (Colomer, 2004; Koplan, Liverman \& Kraak, 2005; Krebs et al., 2007). But in clinical practice, it may be more useful to combine age- and sex-specific BMI values with a body fat assessment capable of detecting a high degree of adiposity to avoid classifying individuals whose high BMI is attributable to a relatively greater fat-free mass or an athletic build as obese (Serra Majem et al., 2002; Whitlock et al., 2005). Since BMI does not follow a normal distribution in the pediatric age group, several indices have been proposed as alternatives. Of these, the recently described inverted BMI $\left(\mathrm{iBMI}\left[\mathrm{cm}^{2} / \mathrm{kg}\right]\right)$ has been referred to as the most useful and accurate proxy for body fat in adults (Nevill et al., 2011). A recent study in the pediatric age group that used the fat mass determined by dual-energy X-ray absorptiometry (DXA) as a reference found that the $\mathrm{iBMI}$ followed a normal distribution and was a good predictor of 
63 body fat, as was BMI, with iBMI accounting for a greater amount of the variance (Duncan et

64 al., 2014). Although various equations have been proposed to calculate body fat based on

65 skinfolds they are not recommended for use in the pediatric population (Almeida et al., 2016;

66 Truesdale et al., 2016).

67

DXA enables the independent assessment of fat mass, boneless fat-free mass and bone mass (Fields \& Goran, 2000; Kehayias \& Valtueña, 2001) and their distribution in each region of the body. DXA is considered a fast, accurate, and safe method for assessment of body fat (Ellis, 2001), as it is free of the drawbacks of computerized axial tomography and magnetic resonance imaging (Goulding et al., 1996). However, since it is not widely available, this technique is not suitable for large-scale and longitudinal studies. For this reason, several indices (BMI, iBMI, conicity index, etc.) have been proposed to estimate the value obtained by DXA. Other authors have constructed multivariable prediction models that estimate body fat from different skinfolds. These methods have been validated by contrasting the mathematical formula with DXA (reference standard) (Silva et al., 2013; Jensen, Camargo \& Bergamaschi, 2016). Nonetheless, they present great difficulty in routine clinical practice because skinfolds are not as simple to measure or as reproducible as the weight and height of a child. For all these reasons, we aimed to develop and internally validate [intraclass correlation coefficient (ICC) and bootstrapping] a statistical model based on simple parameters (BMI, iBMI, sex and age) to predict body fat. Our goal was a simple tool that could be applied in clinical practice to assess adiposity in children and adolescents. 
85

86

87

88

\section{Study Population}

Patients referred for nutritional problems to the Nutrition, Growth and Metabolism Unit of the Department of Pediatrics of San Juan de Alicante University Hospital. This hospital covers an area of about 220,000 inhabitants in the province of Alicante, which is located in the southeast of Spain and has a total of 1,843,589 inhabitants (National Statistics Institute, 2016). The health system is universal and free for both children and adults. The prevalence of childhood obesity in the province of Alicante is approximately 13.5-18.8\% (Ruiz Pérez et al., 2008). The criterion for referral by the primary care pediatrician was overweight/obesity.

\section{Study design and participants}

We conducted a cross-sectional observational study in patients aged 4 to 18 years who met the following inclusion criteria: having had an initial referred visit to the Nutrition, Growth and Metabolism Unit of San Juan de Alicante University Hospital and a DXA assessment prior to the implementation of dietary measures and lifestyle changes. The exclusion criteria encompassed excess weight secondary to causes other then high caloric nutrition, such as growth hormone deficiency with hormone replacement therapy, syndromic obesity, obesity secondary to other diseases such as hypothyroidism, protracted treatment with corticosteroids or other drugs that could influence energy intake or expenditure, precocious puberty, or neurologic or neuromuscular disorders preventing the patient from walking or exercising normally. The data were collected between July 2007 and July 2016, and all the study children were Caucasian.

\section{Variables and measurements}

Our main outcome variables were body fat (\% total body fat) and fat mass index (FMI, in $\mathrm{kg} / \mathrm{m}^{2}$ ). These were measured with a General Electric Lunar DPXN PRO ${ }^{\mathrm{TM}}$ DXA densitometer 
107 (GE Healthcare, Little Chalfont, Buckinghamshire, United Kingdom). The software of this

108 device is able to obtain measurements for the total weight and percentage of body fat. These

109 parameters were used as the reference standard measurements.

110 As secondary variables we used BMI (in $\mathrm{kg} / \mathrm{m}^{2}$ ), sex (male or female) and age (in years).

111 To obtain the anthropometric measurements (weight and height), we followed a standardized

112 protocol with a stadiometer accurate to $0.1 \mathrm{~cm}$ and a SECA scale accurate to $0.1 \mathrm{~kg}$. Each value

113 was measured twice by a single individual, and the mean of the two measurements was used in

114 the analysis.

115 Sample size calculation

116 The sample collected during the study period was 416 children. This sample was randomly

117 divided into two equal parts $(n=208)$. The first group was used to construct a predictive model

118 (multivariable linear regression) and the second group was used to validate it.

119 Construction: To construct a multiple linear regression model we must look at the relationship

120 between the number of subjects and the number of predictors (subject-to-variable ratio). As a

121 heuristic rule, it was considered that this ratio should be at least 50, which allowed the

122 introduction of four explanatory variables in the predictive model.

123 Validation: The sample consisted of the other 208 subjects. This sample size was very

124 satisfactory in obtaining excellent predictions, since the constructed models had four predictors

125 and coefficients of determination of 0.65 and 0.86 for fat percentage and FMI respectively

126 (Knofczynski \& Mundfrom, 2008). The coefficient of determination values were obtained in the

127 construction sample and were used to determine the sample size of the validation. 


\section{Statistical analysis}

129 Continuous variables (BMI, FMI, age and body fat) were summarized using means and standard 130 deviations. To describe the sex variable, we calculated absolute and relative frequencies. To 131 compare the homogeneity of the construction and validation samples, we performed the t-test

132 and the Pearson's chi-squared test. We calculated the following exponentiations: bases (BMI and 133 age) and exponents (-2, -1, 1 and 2). All the interactions between sex and the exponentiation 134 variables were obtained. In the construction sample $(n=208)$ we aimed to construct a linear 135 regression model to predict body fat. Taking into account that we could only introduce 4 136 explanatory variables (subject-to-variable ratio: one per each fifty subjects) and had 17, we 137 applied the following algorithm in order to select them: we obtained all the possible combinations of 1, 2, 3 and 4 elements from the total (17 variables): 3213 combinations. In other words, we analyzed 6426 different models $(3213 \times 2 \approx 6500)$. In each combination we estimated the linear regression model with them in order to predict the body fat and calculated its coefficient of determination. The combination/model with the maximum coefficient was then selected. The goodness-of-fit of the model was assessed with the ANOVA test. The model was internally validated using bootstrap methodology in the validation sample, calculating the intraclass correlation distribution [two fixed judges (the predicted and observed value) with absolute agreement in the ratings]. In addition, the scatter plot with the estimation and the real

146 parameter was obtained. Finally, we also calculated the Bland \& Altman limits of agreement

147 (Bland \& Altman, 1986). The same process was applied for FMI. We set the level of statistical

148 significance at 0.05. The statistical software used was IBM SPSS Statistics 19 and R 2.13.2. 
150 This study adhered to the ethical principles of the Declaration of Helsinki, and only involved the

151 performance of procedures used in everyday clinical practice. The data were processed

152 safeguarding anonymity and confidentiality, and the study was approved by the corresponding

153 Ethics Committee (Comité Ético de Investigación Clínica del Hospital Universitario de San Juan

154 de Alicante, ref 16/305). Informed consent was not requested from the parents for this study,

155 since it was part of routine clinical practice without any type of intervention. The Ethics

156 Committee approved this procedure.

157

158

\section{RESULTS}

159

We analyzed a total sample of 416 children divided into two parts: 208 children in each group (construction and validation). Table 1 shows the descriptive analysis obtained for each group. Of note were a mean body fat of $43 \%$ and $11.7 \mathrm{~kg} / \mathrm{m}^{2}$ for FMI. No differences were observed in the groups, as all the p-values were greater than 0.05 .

following formulas for the body fat estimation (Table 2):

165

A) Boys: $62.627-11245.580 \cdot \mathrm{BMI}^{-2}-259.114 \cdot \mathrm{BMI}^{-1}+2.310 \cdot \mathrm{Age}^{-0} .151 \cdot \mathrm{Age}^{2}$.

166

B) Girls: $62.627-11245.580 \cdot \mathrm{BMI}^{-2}$.

167 For FMI the optimal model had a coefficient of determination of 0.86 and the formulas 168 for the estimation of this parameter were (Table 2): 
170

172

173

174

175

176

177

178

179

180

181

182

183

184

185

186

187

188

189

190

B) Girls: $18.655+0.007 \cdot \mathrm{BMI}^{2}-293.601 \cdot \mathrm{BMI}^{-1}$.

The intraclass correlation distribution is shown in Figure 1 (internal validation).

Regarding the adjustment between estimations and real values, Figure 2 illustrates that both

values were very similar. Finally, the Bland \& Altman procedure has a good level of agreement, because most of the points were between the limits of agreement (dashed lines) (Fig. 3). So that our equations may be easily applied, they have been included in Supplemental Table S1.

\section{DISCUSSION}

\section{Summary}

We constructed and validated two predictive models to determine body fat and FMI in children with overweight and obesity, using the values obtained by DXA as the reference standard. Both models showed excellent accuracy (ICC>0.75) (Cicchetti, 1994).

\section{Strengths and limitations of the study}

The main strength of the study is the easy and cost-effective calculation of body fat percentage and FMI based on the widely used standard anthropometric measurements (height and weight), age and sex. Although more complex techniques, such as DXA, consume little time and few resources and involve a very low radiation exposure, they are not widely available in health care settings and are more complicated and costly to implement. We also underscore the statistical methodology followed for its construction, which took into account the subject-to-variable ratio of about 6500 models. For validation, the sample size was adequate to obtain excellent predictions. 
bias), but due to ethical and cost-of-care considerations, body fat measurement using DXA was

not justified in children of normal weightand was only performed for other clinical purposes,

such as in patients that required a bone mineral density assessment. On the other hand,

information bias was minimized through the use of fully validated and calibrated devices, and

confounding bias was minimized through the estimation of multivariable models. Thus, our

models can only be applied in children with overweight or obesity. Furthermore, although DXA

is not considered the gold standard for the assessment of body fat because a four-component

model is better (Sopher et al., 2004; Sopher, Shen \& Peitrobeilli,2005; Williams et al., 2006),

DXA is generally considered to provide the most valid estimates in clinical practice (Ellis, 2001).

Finally, the models only included anthropometric parameters; that is they did not consider other

factors associated with body fat (Moliner-Urdiales et al., 2009; van Sluijs et al., 2010; Gómez-

Martínez et al., 2012). Nevertheless, even without these other factors our predictions were still precise.

When comparing our predictive models with the existing literature, we find studies that evaluate a single anthropometric parameter and other authors who developed multivariable predictive models based on skinfolds (Silva et al., 2013; Jensen, Camargo \& Bergamaschi, 2016). We must bear in mind that the studies evaluating a single anthropometric parameter

210 (circumferences of the upper arm, waist, hip and others; ratios such as waist-to-height or waist-to-hip) (Freedman et al., 2004; Freedman et al., 2005; Freedman et al., 2012;

212 Bergman et al., 2011; Goossens et al., 2012; Boeke et al., 2013; Weber et al., 2013; Craig et 213 al., 2014) did not assess the power of this parameter, the interactions with other variables, or 
214 a combination of factors to estimate body fat, which gives greater accuracy to the results

215 obtained in our model. Multivariable models of using skinfolds have the clinical drawback of

216 skinfolds being difficult to measure and the methodological drawback that they did not

217 follow the statistical techniques that yield the highest power in the construction and

218 validation of a multiple linear regression predictive model (interactions, powers,

219 bootstrapping, ICC and testing of approximately 6500 models) (Silva et al., 2013; Jensen,

220 Camargo \& Bergamaschi, 2016). In light of the above, our model clearly provides greater

221 accuracy with respect to the others published in the scientific literature.

222 Implications for research and practice

223 The diagnosis, treatment and follow-up of obesity in the pediatric age group have become a

224 global health priority. Consequently, there is great interest in the healthcare field in the

225 development of quick and accurate tools that can be used in the follow-up of these patients. In

226 this study, we developed formulas for the calculation of body fat percentage and FMI based on

227 BMI, age and sex, which facilitate monitoring of adiposity in the management of these patients,

228 reserving the use of more accurate methods such as DXA for extreme cases.

229

Regarding possible future lines of research, we encourage other authors to externally

validate the equations developed in this paper. The methodology used in this work can be applied

to create new equations for body fat or for other types of parameters, both anthropometric and

232 non-anthropometric. 
235 Body fat percentage and FMI measured by DXA can be accurately estimated in children and

236 adolescents with overweight and obesity using our predictive models based on BMI, age and

237 sex. Our models enable quick calculation of body fat percentage and FMI, thereby

238 simplifying and reducing the use of resources in everyday clinical practice. We also

239 highlight our methodology, which could be applied to obtain similar equations for the

240 analyzed parameters.

241

242 ACKNOWLEDGMENTS

243 The authors thank Maria Repice and Ian Johnstone for their review of the English version of 244 this paper. 
245

246

247

248

249

250

251

252

253

254

255

256

257

258

259

260

261

262

263

264

\section{REFERENCES}

Almeida SM, Furtado JM, Mascarenhas P, Ferraz ME, Silva LR, Ferreira JC, Monteiro M, Vilanova M, Ferraz FP. 2016. Anthropometric predictors of body fat in a large population of 9-year-old school-aged children. Obesity Science \& Practice 2: 272-281.

Ballabriga A, Carrascosa A. 2006. Obesidad en la infancia y adolescencia. In: Ballabriga A, Carrascosa A, eds. Nutrición en la Infancia y adolescencia. Madrid, Spain: Ediciones Ergon, 667-703.

Bergman RN, Stefanovski D, Buchanan TA, Sumner AE, Reynolds JC, Sebring NG, Xiang AH, Watanabe RM. 2011. A better index of body adiposity. Obesity (Silver Spring) 19: 1083-1089.

Bland JM, Altman DG. 1986. Statistical methods for assessing agreement between two methods of clinical measurement. Lancet 1: 307-310.

Boeke CE, Oken E, Kleinman KP, Rifas-Shiman SL, Taveras EM, Gillman MW. 2013. Correlations among adiposity measures in school-aged children. BMC Pediatrics 13:99. Cicchetti DV. 1994. Guidelines, criteria, and rules of thumb for evaluating normed and standardized assessment instruments in psychology. Psychology Assessment 6: 284-290. Cole TJ, Lobstein T. 2012. Extended international (IOTF) body mass index cut-offs for thinness, overweight and obesity. Pediatric Obesity 7: 284-294.

Colomer J. 2004. Prevención de la obesidad infantil. Available at http://www.aepap.org/previnfad/pdfs/previnfad_obesidad.pdf (accessed May 2016). 
265 Craig E, Bland R, Ndirangu J, Reilly JJ. 2014. Use of mid-upper arm circumference for

266 determining overweight and overfatness in children and adolescents. Archives of Disease in

267 Childhood 99: 763-766.

268 Duncan MJ, Martins C, Silva G, Marques E, Mota J, Aires L. 2014. Inverted BMI rather

269 than BMI is a better predictor of DEXA determined body fatness in children. European

270 Journal of Clinical Nutrition 68: 638-640.

271 Ellis KJ. 2001. Selected body composition methods can be used in obesity studies. Journal

272 of Nutrition 131: 1589-1595.

273 Fields DA, Goran MI. 2000. Body composition techniques and the four-compartment model

274 in children. Journal of Applied Physiology 89: 613-620.

275 Freedman DS, Thornton JC, Mei Z, Wang J, Dietz WH, Pierson RN Jr, Horlick M. 2004.

276 Height and adiposity among children. Obesity Research 12: 846-853.

277 Freedman DS, Thornton JC, Pi-Sunyer FX, Heymsfield SB, Wang J, Pierson RN Jr, Blanck

278 HM, Gallagher D. 2012. The body adiposity index (hip circumference $\div$ height $(1.5)$ ) is not a

279 more accurate measure of adiposity than is BMI, waist circumference, or hip circumference.

280 Obesity (Silver Spring) 20: 2438-2444.

281 Freedman DS, Wang J, Maynard LM, Thornton JC, Mei Z, Pierson RN, Dietz WH, Horlick

282 M. 2005. Relation of BMI to fat and fat-free mass among children and adolescents.

283 International Journal of Obesity 29:1-8.

284 Gómez-Martínez S, Martínez-Gómez D, Perez de Heredia F, Romeo J, Cuenca-Garcia M,

285 Martín-Matillas M, Castillo M, Rey-López JP, Vicente-Rodriguez G, Moreno L, Marcos A. 
286 2012. Eating habits and total and abdominal fat in Spanish adolescents: influence of physical

287 activity. The AVENA study. Journal of Adolescent Health 50: 403-409.

288 Goossens S, Bekele Y, Yun O, Harczi G, Ouannes M, Shepherd S. 2012. Mid-upper arm

289 circumference based nutrition programming: evidence for a new approach in regions with

290 high burden of acute malnutrition. PLoS One 7: e49320.

291 Goulding A, Taylor RW, Gold E, Lewis-Barned NJ. 1996. Regional body fat distribution in

292 relation to pubertal stage: a dual-energy X-ray absorptiometry study of New Zealand girls

293 and young women. American Journal of Clinical Nutrition 64: 546-551.

294 Himes JH, Dietz WH. 1994. Guidelines for overweight in adolescent preventive services:

295 recommendations from an expert committee: the Expert Committee on Clinical Guidelines

296 for Overweight in Adolescent Preventive Services. American Journal of Clinical Nutrition

297 59: 307-16.

298 Instituto Nacional de Estadística. 2016. Cifras de población y censos demográficos.

299 Available at http://www.ine.es (accessed October 2016).

300 Jensen NS, Camargo TF, Bergamaschi DP. 2016. Comparison of methods to measure body

301 fat in 7-to-10-year-old children: a systematic review. Public Health 133: 3-13.

302 Kehayias J, Valtueña S. 2001. Measurement of body fat mass in vivo: from two-

303 compartment techniques to neutron activation analysis and DXA. Medicina Clínica 116:

$304 \quad 590-597$.

305 Knofczynski GT, Mundfrom D. 2008. Sample Sizes When Using Multiple Linear

306 Regression for Prediction. Educational and Psychological Measurement 68: 431-442. 
307 Koplan JP, Liverman CT, Kraak VI; Committee on Prevention of Obesity in Children and

308 Youth. 2005. Preventing childhood obesity: health in the balance: executive summary.

309 Journal of the American Dietetic Association 105: 131-138.

310 Krebs NF, Himes JH, Jacobson D, Nicklas TA, Guilday P, Styne D. 2007. Assessment of

311 child and adolescent overweight and obesity. Pediatrics 120 Suppl 4: S193-228. Review.

312 Moliner-Urdiales D, Ruiz JR, Ortega FB, Rey-Lopez JP, Vicente-Rodriguez G, España-

313 Romero V, Munguía-Izquierdo D, Castillo MJ, Sjöström M, Moreno LA; HELENA Study

314 Group. 2009. Association of objectively assessed physical activity with total and central

315 body fat in Spanish adolescents; the HELENA Study. International Journal of Obesity

316 (London) 33: 1126-1135.

317 Nevill AM, Stavropoulos-Kalinoglou A, Metsios GS, Koutedakis Y, Holder RL, Kitas GD,

318 Mohammed MA. 2011. Inverted BMI rather than BMI is a better proxy for percentage of

319 body fat. Annals of Human Biology 38: 681-684.

320 Power C, Lake JK, Cole TJ. 1997. Measurement and long-term health risks of child and

321 adolescents fatness. International Journal of Obesity and Related Metabolic Disorders 21:

$322 \quad 507-526$.

323 Prentice AM. 1998. Body mass index standards for children. Are useful for clinicians but not

324 for yet for epidemiologists. BMJ 317: 1401-1402.

325 Ruiz Pérez L, Zapico Álvarez-Cascos M, Zubiaur Cantalapiedra A, Sánchez-Paya J, Flores

326 Serrano J. 2008. Increase in the prevalence of overweight and obesity in the pediatric

327 population of the province of Alicante (Spain) in the last 10 years. Endocrinologia y

328 Nutrición 55: 389-395. 
329 Serra Majem L, Aranceta Bartrina J, Pérez Rodrigo C, Moreno Esteban B, Tojo Sierra R, 330 Delgado Rubio A, Grupo colaborativo AEP-SENC-SEEDO. 2002. Dossier de Consenso.

331 Curvas de referencia para la tipificación ponderal. Población Infantil y Juvenil. Madrid, 332 Spain, IM\&C.

333 Silva DR, Ribeiro AS, Pavão FH, Ronque ER, Avelar A, Silva AM, Cyrino ES. 2013.

334 Validity of the methods to assess body fat in children and adolescents using multi335 compartment models as the reference method: a systematic review. Revista da Associação 336 Médica Brasileira 59: 475-486.

337 Sopher A, Shen E, Peitrobeilli A. 2005. Pediatric body composition methods. In: Heymsfield 338 S, Lohman T, Wang Z, eds. Human body composition, 2nd ed. Champaign, IL: Human 339 Kinetics, 129-140.

340 Sopher AB, Thornton JC, Wang J, Pierson RN Jr, Heymsfield SB, Horlick M. 2004.

341 Measurement of percentage of body fat in 411 children and adolescents: a comparison of 342 dual-energy X-ray absorptiometry with a four-compartment model. Pediatrics 113: 12853431290.

344 Truesdale KP, Roberts A, Cai J, Berge JM, Stevens J. 2016. Comparison of Eight Equations 345 That Predict Percent Body Fat Using Skinfolds in American Youth. Childhood Obesity 12: $346 \quad 314-323$.

347 van Sluijs EM, Page A, Ommundsen Y, Griffin SJ. 2010. Behavioural and social correlates 348 of sedentary time in young people. British Journal of Sports Medicine 44: 747-755. 
349 Weber DR, Moore RH, Leonard MB, Zemel B. 2013. Fat and lean BMI reference curves in

350 children and adolescents and their utility in identifying excess adiposity compared with BMI

351 and percentage body fat. American Journal of Clinical Nutrition 98: 49-56.

352 Whitlock EP, Williams SB, Gold R, Smith PR, Shipman SA. 2005. Screening and

353 interventions for childhood overweight: a summary of evidence for the US Preventive

354 Services Task Force. Pediatrics 116: e125-144. Review.

355 Williams JE, Wells JC, Wilson CM, Haroun D, Lucas A, Fewtrell MS. 2006. Evaluation of

356 Lunar Prodigy dual-energy X-ray absorptiometry for assessing body composition in healthy

357 persons and patients by comparison with the criterion 4-component model. American

358 Journal of Clinical Nutrition 83: 1047-1054. 
Figure 1

Intraclass correlation coefficient distribution of the estimated parameters obtained through the bootstrap methodology.
A, body fat; $B$, fat mass index. 

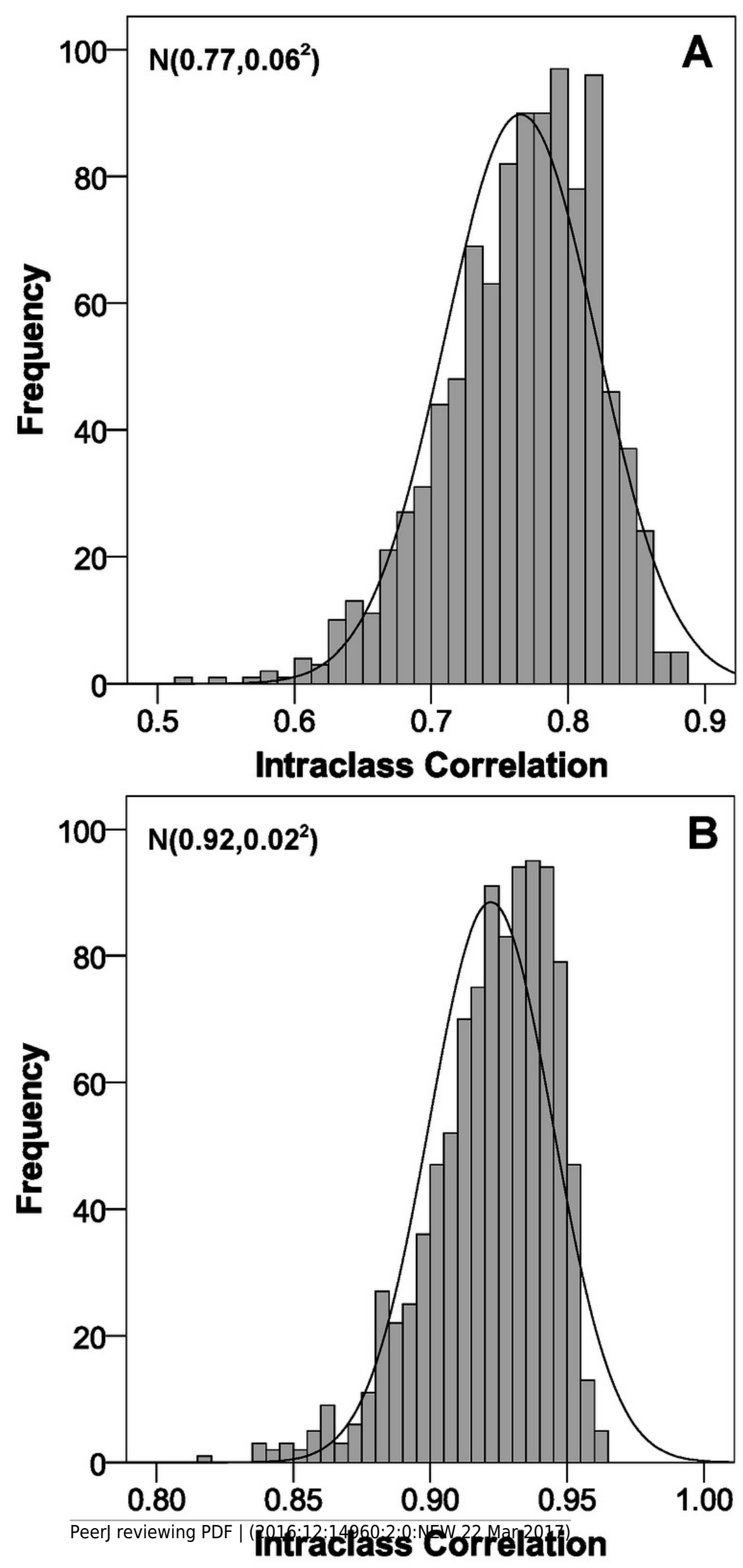
Figure 2

Scatter plot to show the adjustment between the proposed formulas (estimations) and the real parameters in the validation sample.
A, body fat; $B$, fat mass index. 

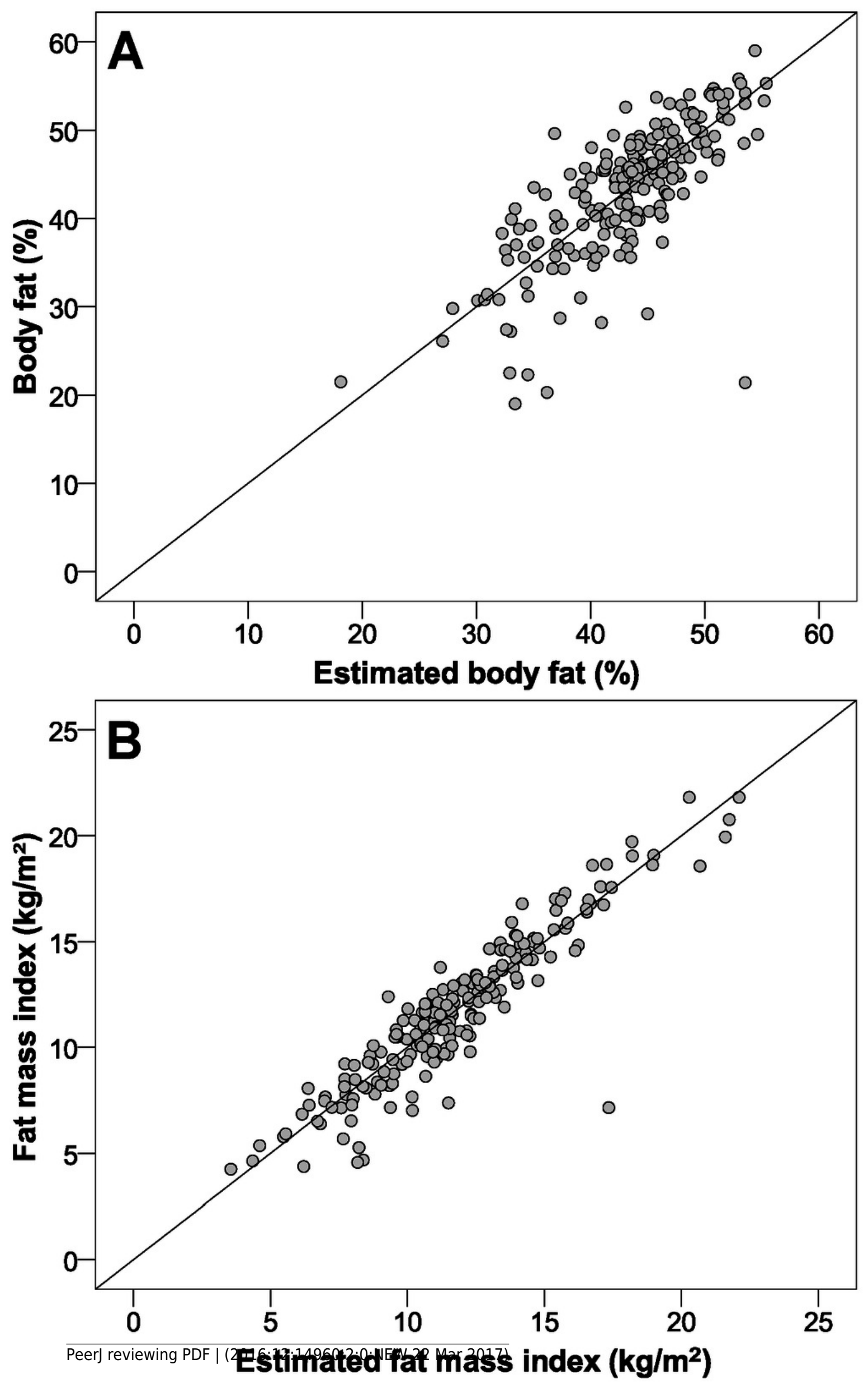


\section{Figure 3}

The Bland \& Altman plot for our proposed formulas.

$\mathrm{Cl}$, confidence interval; SD, standard deviation. The dashed lines are the limits of agreement $( \pm 1.96 \mathrm{SD})$. A, body fat; $B$, fat mass index. 

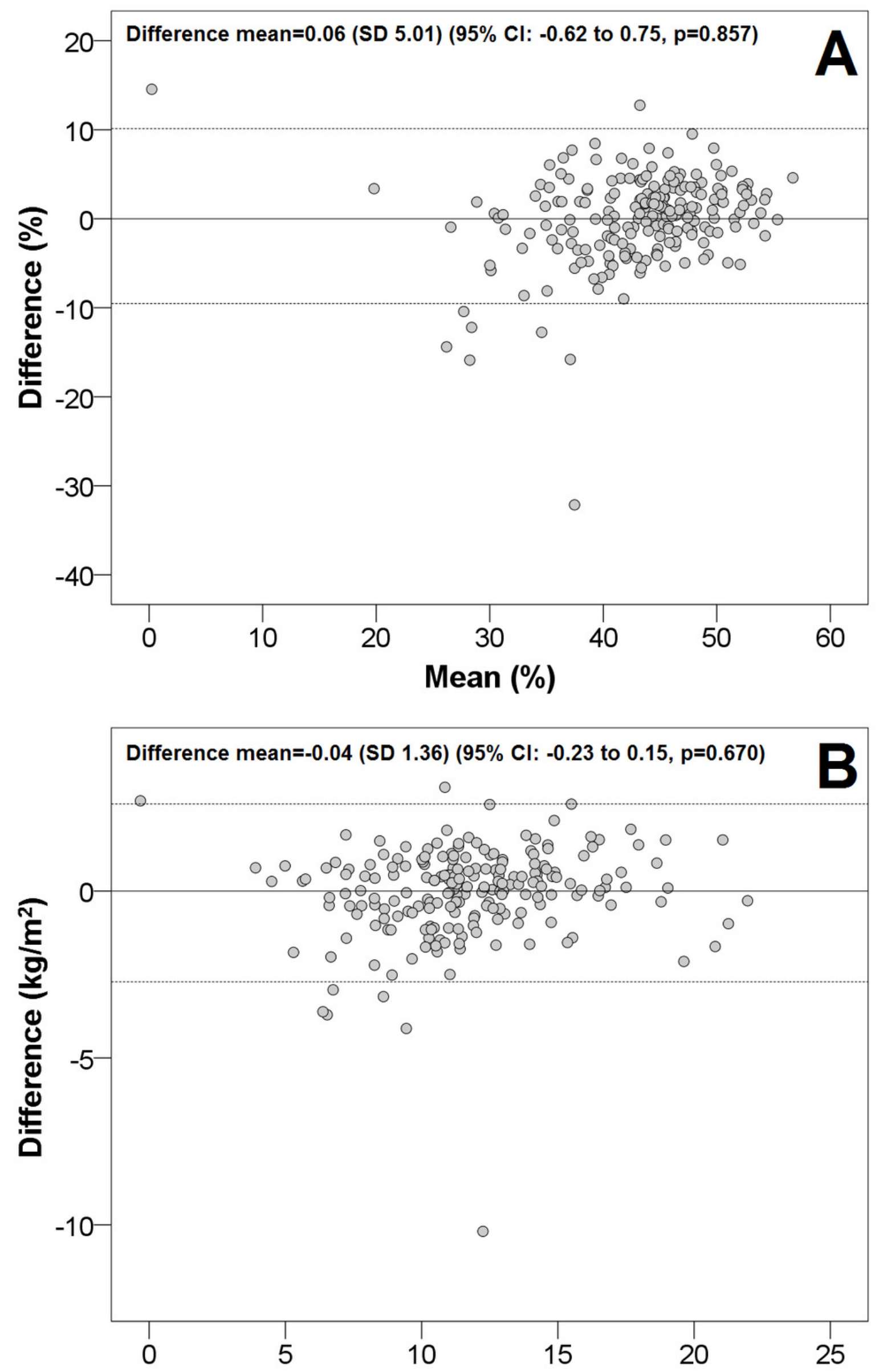


\section{Table $\mathbf{1}$ (on next page)}

Descriptive and comparative analysis for construction and validation samples.

Abbreviations: BMI, body mass index; FMI, fat mass index; $n(\%)$, absolute frequency (relative frequency); $\mathrm{x} \pm \mathrm{s}$, mean \pm standard deviation. *, measured by dual -energy X-ray absorptiometry; b, Pearson's chi-squared test (qualitative variables) or t-test (quantitative variables). 


\begin{tabular}{|l|c|c|c|}
\hline \multirow{2}{*}{ Variable } & Construction sample & Validation sample & \\
& $\mathrm{n}=208$ & $\mathrm{n}=208$ & $\mathrm{p}$-value \\
& $\mathrm{n}(\%) / \mathrm{x} \pm \mathrm{s}$ & $\mathrm{n}(\%) / \mathrm{x} \pm \mathrm{s}$ & \\
\hline Body fat $(\%)^{\mathrm{a}}$ & $43.2 \pm 8.2$ & $43.1 \pm 7.9$ & 0.914 \\
\hline FMI $\left(\mathrm{kg} / \mathrm{m}^{2}\right)^{\mathrm{a}}$ & $11.7 \pm 3.5$ & $11.7 \pm 3.5$ & 0.986 \\
\hline BMI $\left(\mathrm{kg} / \mathrm{m}^{2}\right)$ & $26.6 \pm 4.0$ & $26.7 \pm 4.3$ & 0.918 \\
\hline Male sex & $111(53.4)$ & $113(54.3)$ & 0.844 \\
\hline Age (years) & $11.4 \pm 2.8$ & $11.3 \pm 2.8$ & 0.777 \\
\hline
\end{tabular}

1 


\section{Table 2 (on next page)}

Optimal multivariate models in order to predict our main outcome variables.

Abbreviations: B, regression coefficient; $\mathrm{BMI}$, body mass index; $\mathrm{Cl}$, confidence interval; $\mathrm{FMI}$, fat mass index; N/M, not in the model. Goodness-of-fit of the models (ANOVA test): 1) body fat: $F=94.404, p<0.001 ; 2) F M I: F=319.299, p<0.001$. 


\begin{tabular}{|l|c|c|c|c|}
\hline & \multicolumn{2}{|c|}{ Body fat model } & \multicolumn{2}{c|}{ FMI model } \\
\hline Variable & B (95\% CI) & p-value & B (95\% CI) & $p$-value \\
\hline Constant & $62.627(59.828,65.426)$ & $<0.001$ & $18.655(14.106,23.203)$ & $<0.001$ \\
\hline BMI $^{-2}$ & $-11245.580(-12997.421,-9493.738)$ & $<0.001$ & N/M & N/M \\
\hline BMI $^{-1} \cdot$ Male sex & $-259.114(-443.278,-74.949)$ & 0.006 & N/M & N/M \\
\hline Age· Male sex & $2.310(0.887,3.732)$ & 0.002 & $0.112(-0.010,0.234)$ & 0.073 \\
\hline Age $^{2} \cdot$ Male sex & $-0.151(-0.220,-0.082)$ & $<0.001$ & $-0.018(-0.027,-0.009)$ & $<0.001$ \\
\hline BMI $^{2}$ & N/M & N/M & $0.007(0.005,0.009)$ & $<0.001$ \\
\hline BMI $^{-1}$ & N/M & N/M & $-293.601(-374.123,-213.079)$ & $<0.001$ \\
\hline
\end{tabular}

